\title{
A study on assessment of implications of perceived family well being on self, family and society by husbands and wives of nuclear families belonging to expanding stage of family life cycle in Udaipur city
}

\section{Neetu Singh and Suman Audichya}

Received: 14.02.2020; Revised: 10.11.2020; Accepted: 28.11.2020

See end of the paper for authors' affiliations Neetu Singh

Department of Home Science, Nitishwar Mahavidayalaya, Brabu, Muzaffarpur (Bihar) India Email : neetusingh31cd@gmail. com
ABSTRACT : The study was undertaken to assess the implications of perceived family well being on self, family and society by nuclear urban families belonging to expanding stage of family life cycle. The study was based upon the sample of 100 nuclear families (100 husbands and 100 wives) belonging to middle socio-economic status, selected purposively from Udaipur city. Data was collected through an implications proforma developed by an investigator. Dimensions wise implications of perceived family well being by nuclear families shows that the majority $(90 \%)$ of the husbands gave $2^{\text {nd }}$ ranking to family followed by 75 per cent who gave $1^{\text {st }}$ rank to self and 54 per cent gave $3^{\text {rd }}$ ranking to society. Whereas, ranking by wife's data reveals that the majority ( $83 \%$ ) of the wives gave $2^{\text {nd }}$ rank to self followed by 72 per cent who gave $1^{\text {st }}$ rank to family and 52 per cent gave $3^{\text {rd }}$ ranking to society.

KEY WORDS: Implications, Perceived family well being, Self, Family, Society, Husbands, Wives, Nuclear families, Expanding stage of family life cycle

- HOW TO CITE THIS PAPER : Singh, Neetu and Audichya, Suman (2020). A study on assessment of implications of perceived family well being on self, family and society by husbands and wives of nuclear families belonging to expanding stage of family life cycle in Udaipur city. Asian J. Home Sci., 15 (2) : 409412, DOI: 10.15740/HAS/AJHS/15.2/409-412. Copyright@ 2020: Hind Agri-Horticultural Society.
$\mathrm{T}$ The influence of family in our lives is powerful. The intact family appears to offer a myriad of benefits for adults and children. The married home tends to provide a safer and heal thier home environment. Children from intact families are better in school, exhibit fewer behavioural problems, and are more likely to form healthy romantic relationships as adults. Yet, its influence is difficult to explain because of its complexity both in structure and in the nature of its consequences (Webster and Wright, 1999). As we move into the $21^{\text {st }}$ Century, the role of family is changing even faster than in the past. According to Dreman (1997), changes in family 